\title{
Social Status and the Desire to Resort to Violence: Using the Example of Uganda's Former Child Soldiers
}

\author{
ANSELM CROMBACH, ROLAND WEIERSTALL, TOBIAS HECKER, \\ INGA SCHALINSKI, and THOMAS ELBERT \\ Department of Psychology, University of Konstanz, Konstanz, Germany
}

\begin{abstract}
Committing violent acts can be appealing, fascinating, exciting, and addictive (i.e., appetitive). Cultural settings that accept violence as a means to power and success promote this appetitive form of aggression. Former child soldiers of Uganda with military rank reported committing a greater variety of violent acts compared to those without rank. They experienced aggressive behavior as more positive than both those without rank and controls who had never been involved in armed groups. The relation between the number of individually committed offense types and appetitive aggression is weaker in former child soldiers without rank compared to those with rank. This indicates that the potential for rapid development of appetitive aggression is rewarded with higher social status in war-afflicted communities.
\end{abstract}

KEYWORDS aggression, child soldiers, exposure to violence, offender/perpetrator, social status, war/conflict/terrorism

Violence and atrocities are common and are not only integral to wars and massacres, but also part of the routine work of police and military interrogators. They are present in social interactions across gender and age groups and are practiced early in children's play (Nell, 2006; Tremblay et al., 1999). What drives people to use violence so frequently? Moreover, what motivates the escalation from simple violence to extreme brutality? For example,

Received 28 March 2012; revised 12 August 2012; accepted 14 August 2012.

Address correspondence to Anselm Crombach, Department of Psychology, University of Konstanz, P.O. Box 23/25, 78457 Konstanz, Germany. E-mail: anselm.crombach@unikonstanz.de 
rather than quickly killing victims, some Ugandan rebels brutally butchered people and even went so far as to burn a 3-year-old (e.g., Ertl, Pfeiffer, Schauer, Elbert, \& Neuner, 2011; Pfeiffer \& Elbert, 2011). What makes a man so hungry for cruelty that he loses all moral scruples? Previous research has identified gain in social status (Shackelford, Pound, \& Goetz, 2005), wealth (Anderson \& Bushman, 2002), and superior reproductive success (Wilson, Daly, \& Pound, 2002) as major goals that likely motivate violent behavior. Yet, until recently the possibility that committing cruel and violent acts in itself has intrinsic rewarding effects has received little attention (Elbert, Weierstall, \& Schauer, 2010). Nell (2006) proposed an innate and "strongly male-gendered" human blood lust that can be seen in such phenomena as the fascination of bystanders for violent acts, game hunting in peaceful regions, or the intentional mutilation of victims in war-affected regions. The appetitive experience of committing violence, with all of its appealing, exciting, and potentially addiction-like attributes, can be observed in species close to humans, like chimpanzees (Gibbons, 2004). The evolutionary perspective suggests that it facilitates the commitment of aggressive and cruel acts such as hunting but also inter- and intraspecies aggression as a primary reinforcer and thereby increases the probability of gaining secondary rewards such as food or reproductive success. For example, in chimpanzee populations, it has been shown that the elimination of neighboring tribes facilitates food supply as well as reproduction and is beneficial for the adults' health (Williams, Oehlert, Carlis, \& Pusey, 2004). Additionally, within human societies, the perpetration of violent acts such as homicide is thought to have developed as an evolutionarily profitable strategy to increase reproductive success (Jones, 2008; Kelly, 2005). Hence it is not surprising that an appetitive experience of committing violent acts has also been mentioned in a multitude of human cultures from warriors in small-scale societies to soldiers of industrial nations and genocide perpetrators ${ }^{1}$ (Grossman, 1995; Hatzfeld, 2004; Konner, 2006). In recent years, multiple studies have been conducted to empirically investigate the impact of this form of aggressive behavior, termed appetitive aggression, on individuals and societies. We define appetitive aggression as the perpetration of violence or the infliction of harm on a victim for the purpose of experiencing violence-related enjoyment. It has been demonstrated with Rwandan genocide perpetrators as well as with soldiers and former combatants in Congo and Columbia that committing violent acts can indeed be highly appetitive (Hecker, Hermenau, Maedl, Elbert, \& Schauer, 2012; Weierstall, Bueno Castellanos, Neuner, \& Elbert, 2013; Weierstall \& Elbert, 2011; Weierstall, Schaal, Schalinski, \& Elbert, 2011).

\footnotetext{
"The more we killed, the more we acquired a taste for it. If you are allowed to act out this lust, it will never let you go again. You could see the lust in our greedy popping eyes. . . It was an unprecedented pleasure for everyone" (authors' translation, Hatzfeld, 2004, p. 53).
} 
Anecdotal evidence from violent men, rapists, police force reservists, and torturers suggests that, in the course of time, the pleasure of harming others emerges as a function of committed atrocities (Baumeister \& Campbell, 1999). It seems that one precondition for the development of appetitive aggression is the opportunity to behave cruelly and to experience the benefits of doing so. Therefore perpetrators create and are in turn created by an immediate social context, a culture of cruelty (Elbert, Rockstroh, Kolassa, Schauer, \& Neuner, 2006; Elbert et al., 2010) that enables them to initiate, sustain, and cope with their brutality (Waller, 2006). In such a culture of cruelty, secondary reinforcers such as wealth gain, social status, or other privileges further reward people for committing atrocities. Social learning and operant reinforcement serve to augment appetitive aggression, leading to even more hideous cruelties.

Appetitive aggression seems to be an especially useful adaptation in societies without law enforcement, because it facilitates killing and committing atrocities (Nell, 2006). This enhances intraspecies cruelty, which is advantageous as it makes punishment and intimidation more effective. Such strategies are used to establish and maintain dominance in relationships, discourage parasites and cheats, discipline offspring or prospective sexual partners, and maintain cooperative behavior (Buss \& Duntley, 2006; CluttonBrock \& Parker, 1995). If a person has the ability and the will to commit atrocities, this discourages others from attacking or threatening him. This protects the cruel individual and others close to him, consequently increasing his reproductive success as well as his social status (Elbert et al., 2010; Nell, 2006). Even today, the readiness to be aggressive and even offensive is an attribute of successful men (e.g., in tribal societies or street gangs; Campbell, 1993; Chagnon, 1988). Individuals who develop appetitive aggression are expected to profit, because their willingness to use violence brings them influence, respect, and power.

To profit in this manner, individuals need to distinguish themselves by behaving cruelly and be recognized for doing so. Thus, it can be postulated that individually committed violent acts contribute much more to the development of appetitive aggression than offenses committed as part of a group. Social psychology research suggests that being part of a group facilitates violence and cruelty through a mechanism called deindividuation. For example, in a study across 27 different cultures, Watson (1973) demonstrated an increased probability of committing atrocities, torture, and killing when warriors hid their identities before going to war. By enhancing the group norms and therefore facilitating violent and cruel behavior, deindividuation seems to lead to a diminished sense of responsibility (Aronson, Wilson, \& Akert, 2004). This mechanism potentially promotes the habituation to violent behavior and thereby contributes to the development of appetitive aggression in early stages. Yet in this setting, both the responsibility for and also the 
experience of control, power, and enjoyment of the violent act are shared by the perpetrators. In contrast, individually committed atrocities likely enforce the development of appetitive aggression in conjunction with the individual's reputation as being someone who is willing to use violence. In a culture of cruelty, such an individual gains increased social status.

We anticipated that these advantages of appetitive aggression would be apparent within the Lord's Resistance Army (LRA), a rebel movement that has terrorized northern Uganda for decades. During the civil war from 1986 until 2006, the LRA abducted between 50,000 and 80,000 people, mainly boys between 10 and 18 years old (Amone-P'Olak, 2004; Blattman \& Annan, 2009; Pham, Vinck, \& Stover, 2009). They were used as soldiers and carriers (Vinck, Pham, Stover, \& Weinstein, 2007). Reports from former child soldiers reveal that they were brutally treated during their abduction and were often forced to kill family members or neighbors (Ertl et al., 2011; Pfeiffer \& Elbert, 2011; Schauer \& Elbert, 2010). They had to fight against troops of the government army, assault villages, torture, and kill (Amone-P'Olak, Garnefski, \& Kraaij, 2007; Vinck et al., 2007). The beginning of the child soldiers' captivity was marked by especially extreme physical and psychological maltreatment (Veale \& Stavrou, 2003). However, this brutal and arbitrary treatment ceased as soon as they became soldiers and obtained weapons. For most of the former child soldiers, rank and their weapon are associated with favorable memories like pride and respect and feelings of recovered control and power (Veale \& Stavrou, 2003). During their time with the rebels, two thirds of the abductees were forced to use violence and one third became soldiers (Blattman \& Annan, 2009). Committing atrocities in such a culture of cruelty facilitates the formation of lust for violence; this effect is especially strong in childhood when brain plasticity is greatest and moral development takes place (Elbert et al., 2006).

We expected that within the LRA, some individuals with a certain disposition might have developed a greater desire for violence as an adaptive behavior. As a result, they should have been driven by a lust for cruelty and power and would have profited by gaining higher social status. Thus former child soldiers who held a rank during their time with the rebels compared to those without rank are expected to report that violence is experienced as more pleasantly exciting and fascinating, and as a consequence, report having committed more crimes. A control group with individuals who have never been abducted should have committed even fewer crimes than former child soldiers without rank, as they had never been integrated into such a culture of cruelty. Due to the randomness of the abductions of children by the LRA in North Uganda, the three groups (the nonabducted children and the former child soldiers, both with and without rank) had equal preconditions. The differences among the abducted children seem therefore to be explained best as a result of the ability to adapt to the cruel setting within the LRA. 


\section{METHODS}

\section{Participants}

All participants lived in a camp for internally displaced people in Pabbo, North Uganda. Over time, the sparse infrastructure of this camp has been expanded to include some long-term housing and basic first-response medical facilities. Although some outlying land has been developed for agriculture, in the face of ever diminishing outside aid, the camp continues to struggle with insufficient food supplies. Young men from different parts of the camp were randomly recruited from the streets to participate in the study.

Interviews were conducted with 83 male participants ranging from 17 to 27 years of age. Of these participants, 42 had been abducted by the LRA and spent between 2 days and 12 years with the rebels. Of those, 18 constituted the group of child soldiers without rank because they held no rank within the LRA. The remaining 24 participants owned a weapon and held at least the rank of a private during their time with the rebels. Therefore they constituted the group of the former child soldiers with rank. To compare our results to a nonabducted control group, we interviewed 41 young men of comparable age that had all experienced the war in North Uganda but who had not spent time as child soldiers in the bush (i.e., less than 1 day of abduction). Table 1 presents the demographic data separately for the three groups. Fisher's Exact tests and a Kruskal-Wallis test did not reveal differences in age, number of displacements, level of education, or marital status among the three groups or in the number of abductions between the child soldiers without and with rank (all $p>.05$ ). According to Mann-Whitney U tests the two abducted groups did not differ in the age of first abduction and in the period since the last demobilization (both $p>.05$ ). As expected, the child soldiers with rank were with the rebels for a significantly longer time $(z=5.29, p<.001)$.

Contrary to other rebel groups, within the LRA there was nearly no alcohol or drug consumption due to the group's religious orientation (Green, 2008; Wessells, 2006). This was true for all participants in this study.

The Ethical Review Board of the University of Konstanz and the Uganda National Council for Science and Technology approved the study and all participants gave their written informed consent. For 2 participants under the age of 18, the guardians gave informed consent. Participants received a financial compensation of 4,000 Ugandan shilling (about \$1.60). All data sets were included in the analyses.

\section{Procedure}

The survey was conducted in September 2009 in a camp for internally displaced people in Pabbo, North Uganda. The semistructured interviews were conducted in private areas, in or around the houses of the respondents within the campgrounds. To guarantee confidentiality the researchers assured that 
TABLE 1 Demographic Data

\begin{tabular}{|c|c|c|c|}
\hline & $\begin{array}{l}\text { Child soldiers } \\
\text { with rank } k^{\mathrm{a}}\end{array}$ & $\begin{array}{l}\text { Child soldiers } \\
\text { without rank }\end{array}$ & $\begin{array}{l}\text { Not abducted } \\
\text { or abducted } \\
\text { less than } 24 \mathrm{hr}^{\mathrm{c}}\end{array}$ \\
\hline \multicolumn{4}{|l|}{ Age } \\
\hline$M$ & 21.4 & 21.7 & 21.3 \\
\hline$S D$ & 2.47 & 2.54 & 2.51 \\
\hline Range & $17-26$ & $17-25$ & $18-27$ \\
\hline \multicolumn{4}{|l|}{$\begin{array}{l}\text { Age at time of the first } \\
\text { abduction }\end{array}$} \\
\hline$M$ & 10.4 & 11.2 & - \\
\hline$S D$ & 3.82 & 3.97 & - \\
\hline Range & $2-16$ & $4-18$ & - \\
\hline \multicolumn{4}{|l|}{ No. $(\%)$} \\
\hline Abducted once & $20(83.3 \%)$ & 17 (94.4\%) & - \\
\hline Abducted twice & $4(16.7 \%)$ & $1(5.6 \%)$ & - \\
\hline \multicolumn{4}{|l|}{$\begin{array}{l}\text { Total duration being abducted } \\
\text { in weeks }\end{array}$} \\
\hline$M$ & 161.1 & 3.4 & - \\
\hline$S D$ & 175.05 & 3.05 & - \\
\hline Range & $4-624$ & $0.2-12$ & - \\
\hline \multicolumn{4}{|l|}{ Rank } \\
\hline Private & $15(62.5 \%)$ & - & - \\
\hline Escort guard & $3(12.5 \%)$ & - & - \\
\hline Escort chief & $1(4.2 \%)$ & - & - \\
\hline Commander & $1(4.2 \%)$ & - & - \\
\hline Sergeant & $1(4.2 \%)$ & - & - \\
\hline 2nd Lieutenant & $1(4.2 \%)$ & - & - \\
\hline 1st Lieutenant & $2(8.3 \%)$ & - & - \\
\hline \multicolumn{4}{|l|}{ Years since last demobilization } \\
\hline$M$ & 7.7 & 10.3 & - \\
\hline$S D$ & 3.97 & 4.08 & - \\
\hline Range & $1-7$ & $4.0-16.9$ & - \\
\hline \multicolumn{4}{|l|}{ No. (\%) of displacements } \\
\hline 0 & $1(4.2 \%)$ & 0 & 0 \\
\hline 1 & $5(20.8 \%)$ & $4(22.2 \%)$ & $9(22 \%)$ \\
\hline 2 & $4(16.7 \%)$ & $6(33.3 \%)$ & $15(36.6 \%)$ \\
\hline 3 & $5(20.8 \%)$ & $3(16.7 \%)$ & $7(17.1 \%)$ \\
\hline$>4$ & $8(33.4 \%)$ & $5(27.8 \%)$ & $9(21.9 \%)$ \\
\hline Missing & $1(4.2 \%)$ & 0 & $1(2.4 \%)$ \\
\hline \multicolumn{4}{|l|}{ Education, No. (\%) } \\
\hline No school/some primary & $9(37.5 \%)$ & $4(22.2 \%)$ & $15(36.6 \%)$ \\
\hline Primary school & $1(4.2 \%)$ & $4(22.2 \%)$ & $4(9.8 \%)$ \\
\hline Vocational school & $3(12.5 \%)$ & $1(5.6 \%)$ & $5(12.2 \%)$ \\
\hline Some secondary school & $5(20.8 \%)$ & $9(50 \%)$ & $11(26.8 \%)$ \\
\hline Secondary school & $6(25.0 \%)$ & 0 & $6(14.6 \%)$ \\
\hline \multicolumn{4}{|l|}{ Marital status, No. (\%) } \\
\hline Single & $17(70.8 \%)$ & $7(38.9 \%)$ & $25(61 \%)$ \\
\hline Married & $3(12.5 \%)$ & $3(16.7 \%)$ & $5(12.2 \%)$ \\
\hline Partner/cohabiting & $4(16.7 \%)$ & $8(44.4 \%)$ & $10(24.4 \%)$ \\
\hline Divorced & & & $1(2.4 \%)$ \\
\hline
\end{tabular}

${ }^{\mathrm{a}} n=24 .{ }^{\mathrm{b}} n=18 .{ }^{\mathrm{c}} n=41$. 
no other person was present or could listen to the interviews. The interviews were conducted in Acholi with the help of five local counselors who had been trained in the concepts of mental disorders and aggression (Ertl et al., 2010). All questionnaires were translated into Acholi and back into English by different interpreters and the results of the translation procedure were discussed in detail with the interpreters before the application of the interview.

\section{Measures}

\section{Appetitive Aggression Scale}

A person's propensity to perpetrate aggressive acts was assessed using the Appetitive Aggression Scale (AAS; Weierstall \& Elbert, 2011), a semistructured interview that has been validated with more than 1,600 ex-combatants and has been proven to have good psychometric properties. It contains questions regarding the appetitive perception of aggression. Each item is scored on a 5-point Likert scale ranging from 0 (I totally disagree) to 4 (I totally agree). The items are based on the definition of the instrumental aggression subtype according to Vitiello and Stoff (1997) and the International Classification of Diseases (10th ed.; World Health Organization, 2008) addiction criteria. Further items were compiled on the basis of interviews with perpetrators about the appetitive experience of perpetrating aggressive acts. Cronbach's alpha coefficient as a measure for reliability of the scale was .85 . In a principal-axis factor analysis, all items loaded statistically significantly onto a single factor accounting for $32 \%$ of the total variance. Moreover, further analyses have revealed that the scale measures a distinct construct of human aggression (for further details, see Weierstall \& Elbert, 2011).

\section{NUMBER OF OFFENSE TYPES}

As a further measure of aggressive behavior, the number of different types of committed offenses was assessed with a list of 17 different types of offenses ranging from physical assault to rape or killings. The offenses could have been perpetrated either individually or as part of a group. Therefore we assessed the number of individually committed offense types as well as offense types committed while in a group. Each offense type was coded as 1 (committed) or 0 (not committed). The number of different committed offense types was summed to a total score.

\section{Data Analysis}

For the detection of group differences concerning the number of individually committed offense types, the number of group committed offense types and appetitive aggression, a multivariate analysis of variance (MANOVA) was 
calculated. Moderated multiple linear regression analysis was used to demonstrate the correlation of the variables in the different groups. The statistical analysis was carried out using SPSS 20.0 and R for Mac OS Version 2.11.1.

\section{RESULTS}

For the assessment of the differences among the nonabducted, the child soldiers without rank, and child soldiers with rank, a MANOVA was calculated with the summed scores of the number of individually committed offense types, the number of group committed offense types, and the AAS as dependent variables and the groups as independent variables. The statistical analyses revealed highly significant differences with strong effect sizes on the multivariate level, $F(6,156)=8.18, p<.001, \eta_{p}^{2}=.24$, and on the univariate level concerning the number of individually committed offense types, $F(2,34.23)=15.43, p<.001, \eta^{2}{ }_{p}=.35$; the number of group committed offense types, $F(2,35.65)=21.65, p<.001, \eta_{\mathrm{p}}^{2}=.35$; and appetitive aggression score, $F(2,38.54)=5.50, p=.008, \eta^{2}{ }_{p}=.15$. According to the Levene's test, the homogeneity of variances could not be assumed for all variables on the univariate level. Thus the $F$ values just presented were all corrected according to Welch, and the Games Howell test was used for the post-hoc tests (Field, 2009). As illustrated in Figure 1, the post-hoc tests showed that the child soldiers with rank exceeded (all $p<.05$ ) the other

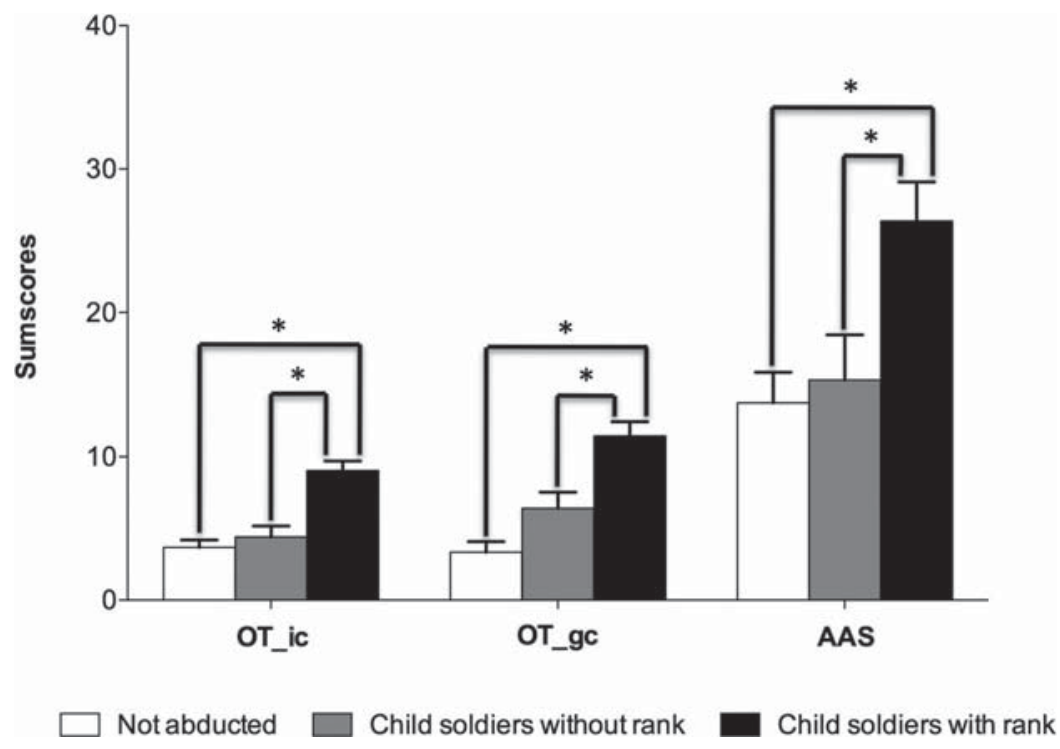

FIGURE 1 Differences between the groups in the number of individually committed offense types (OT_ic), of group committed offense types (OT_gc), and on the Appetitive Aggression Scale (AAS). Means of the groups and standard errors are presented. Asterisks $\left(^{*}\right)$ indicate significant differences. 
two groups by the number of individually committed offense types ( $M=$ 9.04, $S D=4.33)$, the number of group committed offense types $(M=11.46$, $S D=5.24)$, and by appetitive aggression score $(M=26.38, S D=16.38)$. Yet, there were no significant differences between the child soldiers without rank and the nonabducted. The former $(M=4.39, S D=3.42)$ did not report more individually committed offense types than the latter $(M=3.68, S D=$ $2.33, p=.707)$. Similarly the child soldiers without rank $(M=6.39, S D=$ 5.89) did not perpetrate significantly more group committed offense types than the nonabducted $(M=3.34, S D=3.88, p=.131)$. The same was true for the appetitive aggression, as can be seen in Figure 1. The child soldiers without rank $(M=15.28, S D=12.64)$ did not experience violence as more appetitive than the nonabducted $(M=13.76, S D=11.54, p=.900)$.

The group differences showed an overall similar pattern for the number of committed offense types and appetitive aggression scores (Figure 1). The child soldiers with rank had higher scores than the other groups across all categories. Yet, the similar patterns did not indicate whether the individually committed offenses or the group committed offenses contributed more to the development of appetitive aggression, nor did they explain how the latter might have affected the gain of a rank within the LRA. To assess the influence of the individually committed offense types, group committed offense types, and social status and to disentangle the predictive effects, a multiple linear regression analysis was performed. According to the theoretical hypothesis, the score on the AAS was regressed by the number of individually committed offense types, the number of group committed offense types, the group membership, and all interactions among the three variables. For differences between the groups, two dummy-coded variables were created. The reference group was the child soldiers with rank. With the variable dummy_not_abducted they were compared to the nonabducted group, and with the variable dummy_without_rank they were compared to the child soldiers without rank group. For the mitigation of multicollinearity, all predictors were $z$ standardized before the interaction terms were calculated (for methods, see, e.g., Kleinbaum, Kupper, Muller, \& Nizam, 1998). To assess which of the interactions were really important within the model, a backward stepwise regression was applied. Akaike Information Criterion (Akaike, 1987) was used to estimate the model fit.

The selected model (see Table 2) explained $42 \%$ of the variance. It revealed that the prediction of appetitive aggression by the number of individually committed offense types was highly significant. When controlled for the latter, neither the number of group committed offense types nor the belonging to one of the three subgroups added significantly to the explanation of appetitive aggression. Moreover, a highly significant interaction indicated that for the child soldiers without rank, the prediction of appetitive aggression by the number of offense types was considerably weaker than for the child soldiers with rank. In contrast, this was not the case for the nonabducted, as the interaction between dummy_not_abducted and the number 
TABLE 2 Results of the Selected Regression Model Predicting Appetitive Experience of Violence

\begin{tabular}{lcc}
\hline & $\beta$ & $p$ \\
\hline OT_ic & 1.05 & $<.001$ \\
OT_gc & 0.17 & .216 \\
dummy_not_abducted & 0.08 & .555 \\
dummy_without_rank & 0.01 & .930 \\
OT_ic $\times$ dummy_not_abducted & -0.26 & .150 \\
OT_ic $\times$ dummy_without_rank & -0.35 & .009 \\
OT_ic $\times$ OT_gc & -0.39 & .019 \\
\hline
\end{tabular}

Note. Standardized regression coefficients $(\beta)$ are presented for the number of individually committed offense types (OT_ic), the number of group committed offense types (OT_gc), the dummy-coded groups, and significant interactions. $R_{\text {adj. }}^{2}=.42$. dummy_not_abducted $=$ comparison among child soldiers with rank and not abducted; dummy_without_rank = comparison among child soldiers with rank and child soldiers without rank. $N=83$.

of individually committed offense types was not significant. The interaction of individually committed offense types and group committed offense types became negatively significant. This indicated that the strong effect of individually committed offense types on appetitive aggression became smaller in inverse proportion to the number of offense types committed as part of a group.

The scatter plot presented in Figure 2 illustrates the relationship between the number of individually committed offense types and appetitive aggression separately for the different groups. The relationship between the two variables was apparently weaker within the child soldiers without rank than within the other two groups.

As the child soldiers without rank and those with rank differed in the duration of the abduction, this variable could have a possible confounding influence on the presented results. Therefore a multiple regression was conducted with only the abducted to assess whether duration or the interaction between duration and individually committed offense types would influence the appetitive aggression if individually committed offense types were controlled for. All predictors were $z$ standardized. Neither duration $(p=.586)$ nor the interaction $(p=.440)$ had any influence on appetitive aggression.

As Cook's distance only reached a maximum of .14, indicating no significant influence of outliers, no outlying cases were excluded (Tabachnick \& Fidell, 2006).

\section{DISCUSSION}

In this study, a group of formerly abducted child soldiers with and without rank, together with a nonabducted control group, were examined. We were 


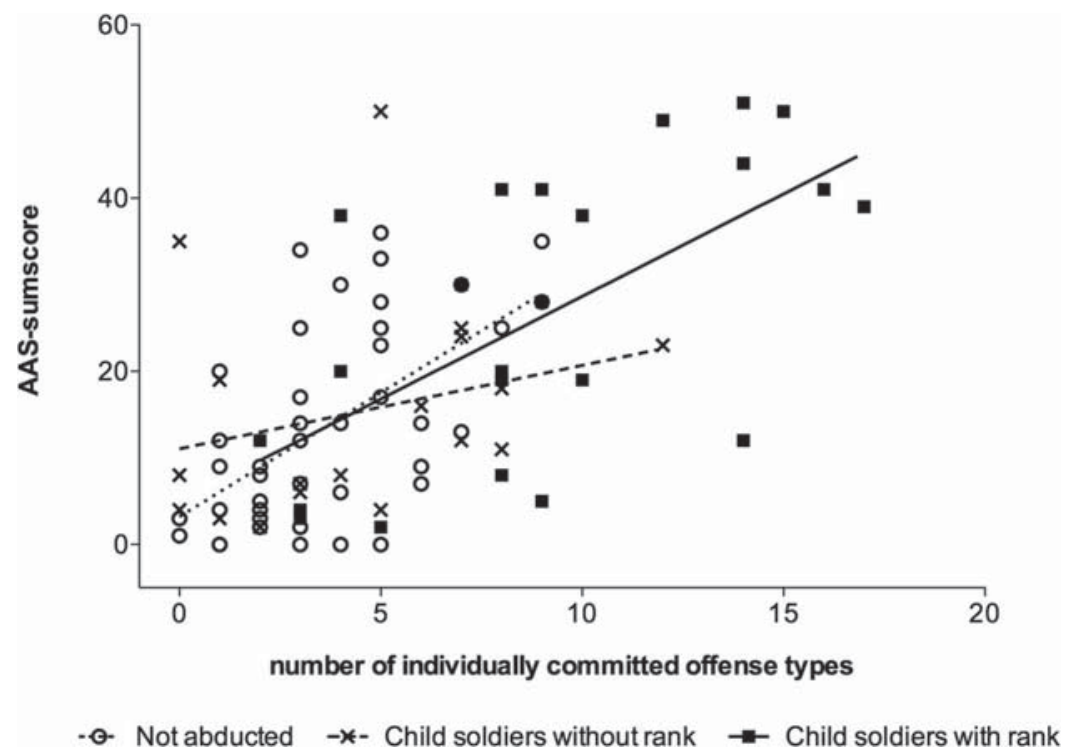

FIGURE 2 Scatterplot of the prediction of the Appetitive Aggression Scale (AAS) by the number of individually committed offense types within different groups. The straight lines indicate the regression lines for each group.

specifically interested in the relationship among social status, appetitive aggression, and the number of offense types committed, either individually or as part of a group. Appetitive aggression was observed in members of all groups, but the extent was much greater in former child soldiers with rank. The same was true for the number of individually and group committed offense types. Furthermore, the individually committed offense types were closely associated with appetitive aggression. This correlation was apparently weaker within the child soldiers without rank than in the other two groups. Additionally when many offense types had been committed as part of a group, the influence of individually committed offense types on appetitive aggression was diminished.

\section{Number of Individually Committed Offense Types and Appetitive Aggression}

Within this study, a firm connection between the number of individually committed offense types and appetitive perception of violence was demonstrated. Hence these results are consistent with studies from Weierstall et al. (2011) and Hecker et al. (2012), in which a corresponding interrelation was shown for Rwandan genocide perpetrators and Congolese ex-combatants. Baumeister and Campbell (1999) suggested that the development of appetitive aggression is a consequence of committing atrocities. 
On the other hand, high appetitive aggression itself likely leads a person to commit atrocities (Nell, 2006). A prospective explanation for the correlation between the number of individually committed offense types and appetitive aggression could be that it represents a vicious cycle driven by both intrinsic and extrinsic reinforcement. Committing atrocities increases appetitive aggression, which in turn enhances the perpetration of atrocities. As former soldiers and genocide perpetrators have described it, such a cycle of violence and cruelty culminates in addiction-like aggressive behavior (Grossman, 1995; Hatzfeld, 2004).

Yet the interrelation between individually committed offense types and appetitive aggression is not equally strong among all groups. It is much weaker within the child soldiers without rank compared to the other two groups, even though the child soldiers without rank were immersed in a culture of cruelty that strengthened the interrelation and facilitated the development of appetitive aggression. There are two possible explanations for this. First it has to be considered that former child soldiers without a rank were with the rebels for a shorter period of time than former child soldiers with rank. They thus experienced only the initial military training period to become a child soldier, which is described by most of them as the worst period of their lives (Veale \& Stavrou, 2003). This might have reduced the impact of the number of offense types on appetitive aggression. But considering that the time spent with the rebels did not influence the interrelation of individually committed offenses and appetitive aggression, this is not a very convincing explanation. Another possibility could be that by dividing the former child soldiers according to their social status, individuals with a high predisposition to develop appetitive aggression are separated from others without such a disposition. In this latter group, due to the slower development of appetitive aggression, the correlation between the number of different offenses and appetitive aggression is not as strong. Therefore, they were not able to adapt well to their cruel environment; that is, they failed to gain social status and suffered psychological strain sufficient enough to drive them out of the rebel groups as soon as they were able to leave.

\section{Appetitive Aggression and Gains in Social Status}

The result that appetitive aggression is higher in former child soldiers who held a rank suggests that higher appetitive aggression is advantageous. Individuals who enjoy committing violence hold a distinct status within the rebel group. As the data presented are cross-sectional, it remains uncertain whether the higher appetitive aggression enabled individuals to gain a rank or if it developed through achievement of a certain rank and the power associated with that rank. Yet the latter explanation seems unlikely, 
as individuals who are not highly motivated to kill and do not resort easily to violence would probably not gain a rank within the LRA. In a study with former Congolese combatants, Hermenau, Hecker, Mädl, Schauer, and Elbert (2013) found that within rebel groups, appetitive aggression is apparently connected to the rank of soldiers having been recruited as children but not of soldiers having been recruited as adults. Whereas the latter usually started with a higher rank from the beginning due to their education and experience, the former needed to impress their superiors by their willingness to use violence to gain social status. This supports the interpretation that appetitive aggression is advantageous in the pursuit of higher social status. Moreover, the same relationship between the number of individually committed offense types and appetitive aggression was found for both the nonabducted and the former child soldiers with rank. This indicates that the appeal of violence did not develop primarily in response to the possession of a rank. It is more likely that individuals with high appetitive aggression gain a superior social status in societies and subcultures in which violence is accepted or even appreciated. The ability to perceive the perpetration of violence as appetitive would thus constitute an advantage in a culture of violence. It not only makes living in such a cultural setting more acceptable, but it also increases the likelihood of survival and brings with it further advantages that come with elevated social status.

\section{Number of Group Committed Offense Types, Appetitive Aggression, and Social Status}

Group committed offense types had no influence on the development of appetitive aggression when controlling for individually committed offense types. This is in line with the assumption that child soldiers need to impress their superiors by their willingness to be aggressive and use violence to gain social status. Moreover it supports the assumption that deindividuation reduces the experience of control, power, and enjoyment of the violent act by diminishing the feeling of responsibility for the violent behavior. Committing violence while being part of a group certainly facilitates the perpetration of cruelties and therefore might enhance the development of appetitive aggression in early stages. However, committing violence as part of a group does not significantly contribute to a cruel reputation and thus does not lead to the acquisition of respect, power, and social status within a rebel group. Only individuals with a predisposition to enjoy aggressive behavior are able to distinguish themselves by individually committing atrocities. They have less need to justify their behavior and attribute it to group norms. Their appetitive aggression motivates them to perpetrate violence individually, seeking a stronger sensation of enjoyment and power and thereby building a reputation and social status within their group. 


\section{LIMITATIONS}

The respondents of this study were former child soldiers who escaped from armed groups months or years earlier. The assessment of appetitive aggression is thereby potentially diminished or biased as a consequence of norms of the society and the susceptibility to giving socially desirable answers to aggression questionnaires (Blümke \& Zumbach, 2007). Therefore the effect might even be stronger in a sample with active fighters. Another indicator for this assumption is the longer duration with the armed groups of the child soldiers with rank. Together with reports from former soldiers and killers, which indicate an addiction to the exertion of violence (Grossman, 1995; Hatzfeld, 2004), it supports the supposition that people with a very high level of appetitive aggression tend to stay longer with rebel groups. Social desirability might also provide an explanation as to why no difference was found between the nonabducted and the child soldiers without rank in the number of committed offenses. Shame, guilt, and fear of consequences, combined with a low appetitive experience of aggression, might have resulted in underreporting of criminal acts, especially by the former child soldiers without rank.

It is obvious that perpetrators themselves also suffer from the consequences of war, and they do not always perceive aggression as appealing. In fact, aggression has often been linked to affect dysregulation, impulsive, uncontrolled behavior that is born of anger, fear, and even post-traumatic stress disorder (Elbert et al., 2006; Ford, 2002; Taft, Vogt, Marshall, Panuzio, \& Niles, 2007). This article does not address these issues but focuses only on appetitive aggression and social status and therefore does not discuss the relationships among appetitive aggression, impulsive and reactive aggression, and mental disorders.

\section{CONCLUSIONS}

This study indicates that strong appetitive aggression is associated with social status and power in a cruel setting. We suggest that its development is a profitable adaptation, which enhances the probability of survival and empowers individuals to gain a higher social status. Furthermore, it can be asserted that this predisposition for the rapid development of strong appetitive aggression is relatively widespread and not limited to a small fraction of potentially psychopathic individuals.

This study highlights the need to consider appetitive aggression as an important factor in understanding aggressive behavior and in particular recurrent cruel behavior in crisis regions and other violent settings. Its development is influenced by a set of different factors and requires interdisciplinary input from social, biological, and evolutionary psychology to be 
properly explained. An important factor seems to be a social environment that is accepting of and that promotes violent behavior. It creates opportunities to experience feelings of power and control through violent and cruel actions without having to fear any consequences. In such conditions, social learning and secondary rewards further reinforce appetitive aggression. Appetitive aggression might begin simply with the feeling of regaining control in insecure and dangerous situations and acting out within the anonymity of a group without having to take full responsibility for his actions. However, soon the feeling of control and power leads to enjoyment of violence and a craving for more. Individually committed atrocities will become more and more appealing for individuals with the predisposition to easily develop appetitive aggression, thereby reinforcing a cycle of violence and cruelty.

\section{REFERENCES}

Akaike, H. (1987). Factor analysis and AIC. Psychometrika, 52, 317-332.

Amone-P'Olak, K. (2004). A study of the psychological state of former abducted children at Gulu World Vision Trauma Centre. Journal on Rehabilitation of Torture Victims and Prevention of Torture, 14(1), 24-34.

Amone-P'Olak, K., Garnefski, N., \& Kraaij, V. (2007). The impact of war experiences and physical abuse on formerly abducted boys in Northern Uganda. South African Psychiatry Review, 10(2), 76-82.

Anderson, C. A., \& Bushman, B. J. (2002). Human aggression. Annual Review of Psychology, 53(1), 27-51.

Aronson, E., Wilson, T. D., \& Akert, R. M. (2004). Sozialpsychologie [Social psychology] (4th ed.). Munich, Germany: Pearson Education.

Baumeister, R. F., \& Campbell, W. K. (1999). The intrinsic appeal of evil: Sadism, sensational thrills, and threatened egotism. Personality and Social Psychology Review, 3, 210-221.

Blattman, C., \& Annan, J. (2009). The consequences of child soldiering. Retrieved from http://www.chrisblattman.com/documents/research/2009. Consequences. RESTAT.pdf

Blümke, M., \& Zumbach, J. (2007). Implicit and explicit measures for analyzing the aggression of computer gamers. In G. Steffgen \& M. Gollwitzer (Eds.), Emotions and aggressive behavior (pp. 38-57). Göttingen, Germany: Hogrefe \& Huber.

Buss, D. M., \& Duntley, J. D. (2006). The evolution of aggression. In M. Schaller, J. A. Simpson, \& D. T. Kenrick (Eds.), Evolution and social psychology (pp. 263-286). New York: Psychology Press.

Campbell, A. (1993). Men, women and aggression. New York: Basic Books.

Chagnon, N. A. (1988). Life histories, blood revenge, and warfare in a tribal population. Science, 239(4843), 985-992.

Clutton-Brock, T. H., \& Parker, G. A. (1995). Punishment in animal societies. Nature, 373(6511), 209-216.

Elbert, T., Rockstroh, B., Kolassa, I.-T., Schauer, M., \& Neuner, F. (2006). The influence of organized violence and terror on brain and mind: A co-constructive 
perspective. In P. Baltes, P. Reuter-Lorenz, \& F. Rösler (Eds.), Lifespan development and the brain: The perspective of biocultural co-constructivism (pp. 326-349). New York: Cambridge University Press.

Elbert, T., Weierstall, R., \& Schauer, M. (2010). Fascination violence-On mind and brain of man hunters. European Archives of Psychiatry and Clinical Neuroscience, 260, 100-105.

Ertl, V., Pfeiffer, A., Saile, R., Schauer, E., Elbert, T., \& Neuner, F. (2010). Validation of a mental health assessment in an African conflict population. Psychological Assessment, 22, 318-324.

Ertl, V., Pfeiffer, A., Schauer, E., Elbert, T., \& Neuner, F. (2011). Communityimplemented trauma therapy for former child soldiers in Northern Uganda: A randomized controlled trial. Journal of the American Medical Association, 206(5), 503-512.

Field, A. (2009). Discovering statistics using SPSS (3rd ed.). London: Sage.

Ford, J. D. (2002). Traumatic victimization in childhood and persistent problems with oppositional-defiance. Journal of Aggression, Maltreatment \& Trauma, 6 , $25-58$.

Gibbons, A. (2004). Chimpanzee gang warfare. Science, 304, 818-819.

Green, M. (2008). The wizard of the Nile. London: Portobello Book.

Grossman, D. (1995). On killing: The psychological cost of learning to kill in war and society. Boston: Little, Brown.

Hatzfeld, J. (2004). Zeit der Macheten: Gespräche mit den Tätern des Völkermordes in Ruanda [A time for machetes: The Rwandan genocide. The killers speak]. Giessen, Germany: Haland \& Wirth im Psychosozial-Verlag.

Hecker, T., Hermenau, K., Maedl, A., Elbert, T., \& Schauer, M. (2012). Appetitive aggression in former combatants-Derived from the ongoing conflict in DR Congo. International Journal of Law and Psychiatry, 35, 244-249.

Hermenau, K., Hecker, T., Mädl, A., Schauer, M., \& Elbert, T. (2013). Growing up in armed groups: Trauma and aggression among child soldiers in DR Congo. Manuscript submitted for publication.

Jones, D. (2008). Human behavior: Killer instincts. Nature, 451(7178), 512-515.

Kelly, R. (2005). The evolution of lethal intergroup violence. Proceedings of the National Academy of Science, 102, 15294-15298.

Kleinbaum, D. G., Kupper, L. L., Muller, K. E., \& Nizam, A. (1998). Applied regression analysis and other multivariable methods (3rd ed.). Pacific Grove, CA: Duxbury.

Konner, M. (2006). Human nature, ethnic violence and war. In M. Fitzduff \& C. E. Stout (Eds.), The psychology of resolving global conflicts: From war to peace. Nature vs. nurture (Vol. 1, pp. 1-40). Westport, CT: Praeger Security International.

Nell, V. (2006). Cruelty's rewards: The gratifications of perpetrators and spectators. Behavioral and Brain Sciences, 29(3), 211-224.

Pfeiffer A., \& Elbert T. (2011). PTSD, depression and anxiety among former abductees in Northern Uganda. Conflict and Health, 5, 14.

Pham, P. N., Vinck, P., \& Stover, E. (2009). Returning home: Forced conscription, reintegration, and mental health status of former abductees of the Lord's Resistance Army in Northern Uganda. BMC Psychiatry, 9, 23.

Schauer, E., \& Elbert, T. (2010). The psychological impact of child soldiering. In E. Matz (Ed.), Trauma rehabilitation after war and conflict (pp. 311-360). New York: Springer. 
Shackelford, T. K., Pound, N., \& Goetz, A. T. (2005). Psychological and physiological adaptations to sperm competition in humans. Review of General Psychology, 9, 228-248.

Tabachnick, B. G., \& Fidell, L. S. (2006). Using multivariate statistics (5th ed.). New York: Pearson Education.

Taft, C. T., Vogt, D. S., Marshall, A. D., Panuzio, J., \& Niles, B. L. (2007). Aggression among combat veterans: Relationships with combat exposure and symptoms of posttraumatic stress disorder, dysphoria, and anxiety. Journal of Traumatic Stress, 20(2), 135-145.

Tremblay, R. E., Japel, C., Perusse, D., Mcduff, P., Boivin, M., Zoccolillo, M., et al. (1999). The search for the age of "onset" of physical aggression: Rousseau and Bandura revisited. Criminal Behaviour and Mental Health, 9(1), 8-23.

Veale, A., \& Stavrou, A. (2003). Violence, reconciliation and identity. The reintegration of Lord's Resistance Army child abductees in Northern Uganda. Retrieved from http://www.issafrica.org/pgcontent.php?UID=3226

Vinck, P., Pham, P. N., Stover, E., \& Weinstein, H. M. (2007). Exposure to war crimes and implications for peace building in Northern Uganda. Journal of the American Medical Association, 298, 543-554.

Vitiello, B., \& Stoff, D. M. (1997). Subtypes of aggression and their relevance to child psychiatry. Journal of the American Academy of Child and Adolescent Psychiatry, 36, 307-315.

Waller, J. (2006). Becoming evil: How ordinary people commit genocide and mass killing. In M. Fitzduff \& C. E. Stout (Eds.), The psychology of resolving global conflicts: From war to peace. Nature vs. nurture (Vol. 1, pp. 89-107). Westport, CT: Praeger Security International.

Watson, R. I. (1973). Investigation into deindividuation using a cross-cultural survey technique. Journal of Personality E Social Psychology, 25, 342-345.

Weierstall, R., Bueno Castellanos, C. P., Neuner, F., \& Elbert, T. (2013). Relations among appetitive aggression, post-traumatic stress and motives for demobilization: A study in former Colombian combatants. Conflict and Health, 7, 9 .

Weierstall, R., \& Elbert, T. (2011). The Appetitive Aggression Scale. European Journal of Psychotraumatology, 2, 8430.

Weierstall, R., Schaal, S., Schalinski, I., \& Elbert, T. (2011). The thrill of being violent as an antidote to trauma-related ill-health. European Journal of Psychotraumatology, 2, 6345.

Wessells, M. G. (2006). Child soldiering: Entry, reintegration, and breaking cycles of violence. In M. Fitzduff \& C. E. Stout (Eds.), The psychology of resolving global conflicts: From war to peace. Interventions (Vol. 3, pp. 243-266). Westport, CT: Praeger Security International.

Williams, J., Oehlert, G., Carlis, J., \& Pusey, A. (2004). Why do male chimpanzees defend a group range? Animal Behavior, 68, 523-532.

Wilson, M., Daly, M., \& Pound, N. (2002). An evolutionary psychological perspective on the modulation of competitive confrontation and risk-taking. In D. W. Pfaff, A. P. Arnold, S. E. Fahrbach, A. M. Etgen, \& R. T. Rubin (Eds.), Hormones, brain and behavior (Vol. 5, pp. 381-408). San Diego, CA: Academic.

World Health Organization. (2008). ICD-10: International statistical classification of diseases and related health problems (10th rev. ed.). Geneva: Author. 